\title{
Effect of ultrasonication on physicochemical properties of apple based nanocellulose-calcium carbonate composites
}

\author{
M. Szymańska-Chargot · Jolanta Cieśla • Monika Chylińska • Karolina Gdula • \\ Piotr M. Pieczywek · Arkadiusz Kozioł · Krystian J. Cieślak • Artur Zdunek
}

Received: 12 February 2018/ Accepted: 6 June 2018/Published online: 11 June 2018

(C) The Author(s) 2018

\begin{abstract}
In order to improve optical properties of materials made of nanocellulose and also minimalize costs, small amounts of mineral fillers such as different forms of calcium carbonate are added. In this work nanocellulose was obtained from apple pomace. The precipitated calcium carbonate (PCC) in amount of $3.74 \pm 1.36 \%$ of a sample dry matter was deposited on cellulose fibers during isolation process. Isolated cellulose was then treated with ultrasonic method in order to obtain apple cellulose nanofibrills (ACNF)/ PCC nanocomposites. Different ultrasonication conditions were applied in order to evaluate how time (0-60 min) and power $(0-400 \mathrm{~W})$ influence on the ACNF/PCC nanocomposites properties. Moreover structure, chemical composition, morphology and
\end{abstract}

rheological properties of both cellulose and composites were characterized. Also the mechanical properties of nanopapers made of ACNF/PCC nanocellulose were measured. The nanofibril structure of ultrasound processed cellulose was confirmed. In all cases samples were pseudoplastic fluids with quite low viscosity. The mean hydrodynamic diameter of particle dispersions decreased the most after use of ultrasounds for $60 \mathrm{~min}$ and the obtained dispersions were also the most homogeneous. The elastic modulus of obtained nanopapers were $2-3 \mathrm{GPa}$ and tensile strength $60-70 \mathrm{MPa}$ and in general ultrasonication improved their rigidity.

Electronic supplementary material The online version of this article (https://doi.org/10.1007/s10570-018-1900-6) contains supplementary material, which is available to authorized users.

M. Szymańska-Chargot $(\bowtie) \cdot$ J. Cieśla ·

M. Chylińska · K. Gdula · P. M. Pieczywek ·

A. Kozioł · A. Zdunek

Institute of Agrophysics, Polish Academy of Sciences,

Doswiadczalna 4, 20-290 Lublin 27, Poland

e-mail: m.szymanska@ipan.lublin.pl

K. J. Cieślak

Faculty of Environmental Engineering, Institute of

Renewable Energy Engineering, Lublin University of

Technology, Nadbystrzycka 40B, Lublin, Poland 


\section{Graphical Abstract}

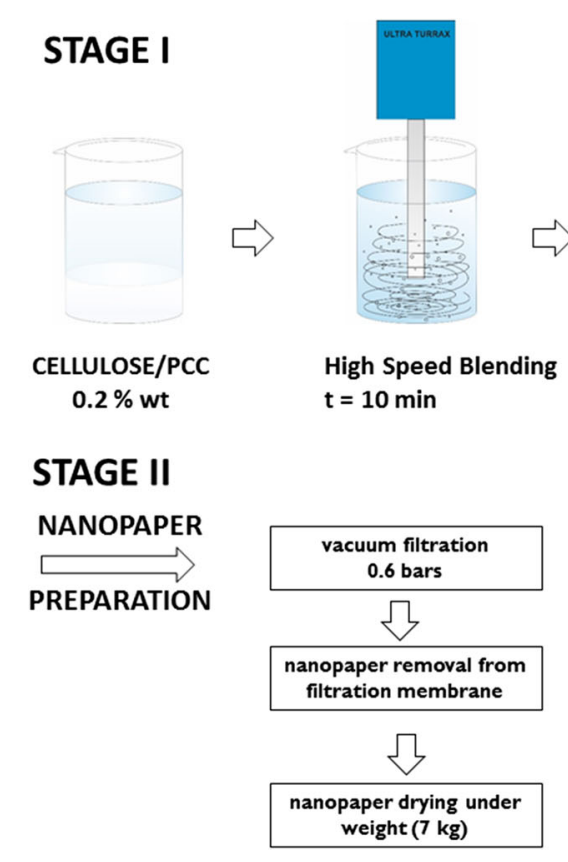

Keywords Nanofibrillated cellulose - Fruit pomace Precipitated calcium carbonate $\cdot$ High-intensity ultrasonication · Hybrid materials

\begin{abstract}
Abbreviations
ACNF Apple cellulose nanofibrills

PCC Precipitated calcium carbonate

HIUS High-intensity ultrasonication
\end{abstract}

\section{Introduction}

Cellulose itself is the most abundant natural polymer on Earth. Cell wall of every plant is kind of composite made of polysaccharides with cellulose as a scaffold (Niklas 1992; Roland et al. 1989). This polymer has unique properties: high mechanical strength and relatively low density. Tensile strength of cellulose fibril is $7.7 \mathrm{GPa}$ which is two times higher than that of steel wire or Kevlar fiber (Brinchia et al. 2013; Moon et al. 2011). There is growing research interest in the use of cellulosic nanomaterials known as nanocellulose such as microfibrillated cellulose, nanofibrillated cellulose and cellulose nanocrystals in papermaking, coatings and films or for nanocomposite technologies (Moon et al. 2011). The different forms of

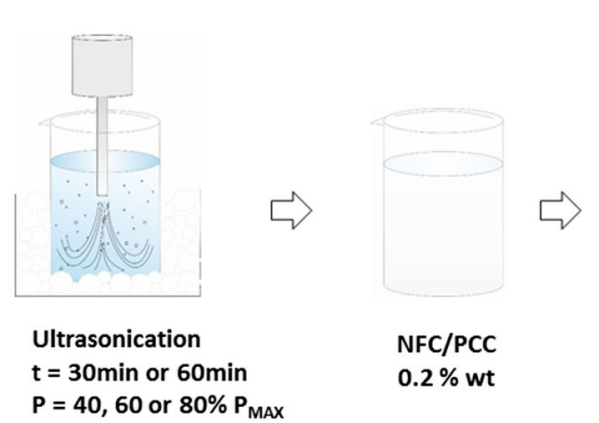

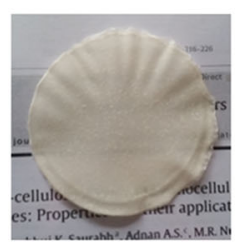

High Speed Blending $\mathbf{t}=10 \mathrm{~min}$

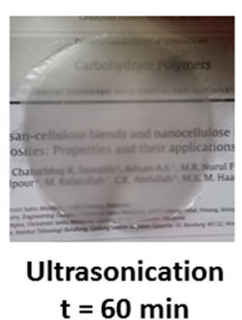

$t=60 \mathrm{~min}$ nanocellulose find its application in many research and industry due to is natural origin, biodegrability and capacity to functionalization (Heinze 2016; Khalil et al. 2012). Among them cellulose nanofibrils (CNF) or microfibrils (CMF) are potential candidates for high filler-loaded papers and boards as they are able to compensate for strength loss caused by the filler itself (Ämmälä et al. 2013). These forms of cellulose exhibit unique properties such as high strength and stiffness. Therefore it was shown that microfibrillated and nanofibrillated cellulose can be used in papermaking applications as strength additives or to enhance barrier properties in food packaging, but also to reduce paper grammage and for smart and sustainable packaging (Osong et al. 2016). The nanocellulose has property of binding water by forming gel-like structure (DimicMisic et al. 2013).

On the other hand, to improve optical properties of cellulose films (paper) and minimize costs small amounts of mineral filler is added. One of the most popular mineral fillers are different forms of calcium carbonate. For example, precipitated calcium carbonate (PCC) added in paper making has the effect of pulp dewatering and enhance the flocculation, but also improve opacity and smoothness of paper (DimicMisic et al. 2016, 2017). The recent studies showed the 
possibility of use the CNF/PCC system as the filler in papermaking process enhancing the flocculation process and improving mechanical properties (Lu et al. 2017).

Most often wood pulp is used as a source of cellulose, however, due to large scale of fruit production and resulting waste, post-fruit processing pomace may be considered as alternative source of cellulose (Heinze 2016; Khalil et al. 2012; Szymańska-Chargot et al. 2017). Wood-derived cellulosic nanomaterials have been recognized as having enormous potential in the field of pulp and paper technology (Subramanian et al. 2011). However, the fruit and vegetable pomace contain even up to $43 \%$ of cellulose with crystallinity degree up to $35 \%$ (Rabetafika et al. 2014). Moreover, the cellulose obtained from fruit cell wall characterize with thinner microfibrils which can give better filler properties (Szymańska-Chargot et al. 2017). Due to the fact that the problem of fruits and vegetables wastes management is still growing therefore this research focuses on cellulose isolation from the pomace made of apple that is the major fruit crop in the world (Dhillon et al. 2013; Mirabella et al. 2014).

High-intensity ultrasonication (HIUS method) has been shown to be effective for $\mathrm{CNF}$ preparation (Osong et al. 2016). Hence, in this study the hybrid material combining the nanofibrillated cellulose produced from apple pomace (ACNF) and in situ precipitated calcium carbonate (PCC) was prepared by the HIUS method. Often the most obvious source of calcium carbonate is simply tap water. From the point of view of the industry, it is a source that does not generate additional costs. Calcium carbonate is already precipitated in the cellulose isolation process, so there is no additional step to enrich the material during its preparation. In order to optimize the process the goal was to evaluate an influence of ultrasound power and process time on cellulose fibrillation and calcium carbonate deposition. The possible use of such mixed organic/inorganic material can be found in paper production and also as packaging materials. Therefore this experiment focuses also on the mechanical properties of obtained nanopapers made of ACNF/ PCC.

\section{Experimental}

Materials

Never-dried cellulose was isolated from apple pomace prepared in a de-pulping machine with a double screw shredder (Twin Gear Juice Extractor, Green Star Elite GSE-5000, Anaheim, CA, USA) due to method described by Szymańska-Chargot et al. (2017). The detailed information about the composition of apple pomace can be found in Szymańska-Chargot et al. (2017). All the isolation procedure was conducted in tap water containing high amounts of calcium carbonate.

Methods

Preparation of cellulose/calcium carbonate dispersions

The procedure of ultrasound treatment and nanopapers preparation is presented in Fig. 1. The $0.2 \% \mathrm{wt}$ suspension of cellulose with precipitated calcium carbonated was prepared and then each time the $250 \mathrm{~g}$ of cellulose/PCC was subjected to ultrasound treatment. First, the Ultra-Turrax (T10 basic ULTRA TURRAX, IKA) was used for $10 \mathrm{~min}$ to disperse obtained suspensions. The sample at this stage was treated as a control sample. Then initially dispersed samples were introduced to ultrasound treatment. The ultrasonic homogenizer Omni Sonic Ruptor 400 equipped with $3 / 8^{\prime \prime}$ sonication probe was used (Omni International, Inc., Kennesaw, Georgia, USA). The sonication system contained temperature probe and to avoid the heating of the sample the ice-bath was used. Operating power of ultrasonic homogenizer ranged from 0 to $400 \mathrm{~W}$. The three different operating powers of $40 \%$ (M40), 60\% (M60) and 80\% (M80) of maximum power and two homogenization times of $30 \mathrm{~min}(\mathrm{t} 30)$ and $60 \mathrm{~min}$ (t60) were used. The relevant ACNF/PCC samples were denoted as M0t0, M40t30, M60t30, M80t30, M40t60, M60t60, M80t60. Such obtained dispersions were filtered under vacuum (0.6 bar) in the system composed of vacuum pump Basic 36 (AgaLabor, Poland) and filtration set (1000 mL flask, funnel and clamp, Chempur, Poland). In every case, a $0.65 \mu \mathrm{m}$ pore diameter PDF membrane filter (EMD Millipore ${ }^{\mathrm{TM}}$ Durapore $^{\mathrm{TM}}, \phi$ $=90 \mathrm{~mm}$ ) was used. The filtration process lasted 
Fig. 1 The procedure of transformation of cellulose/ $\mathrm{PCC}$ suspension to ACNF/ PCC dispersion (STAGE I) and procedure of ACNF/ PCC nanopaper preparation (STAGE II)

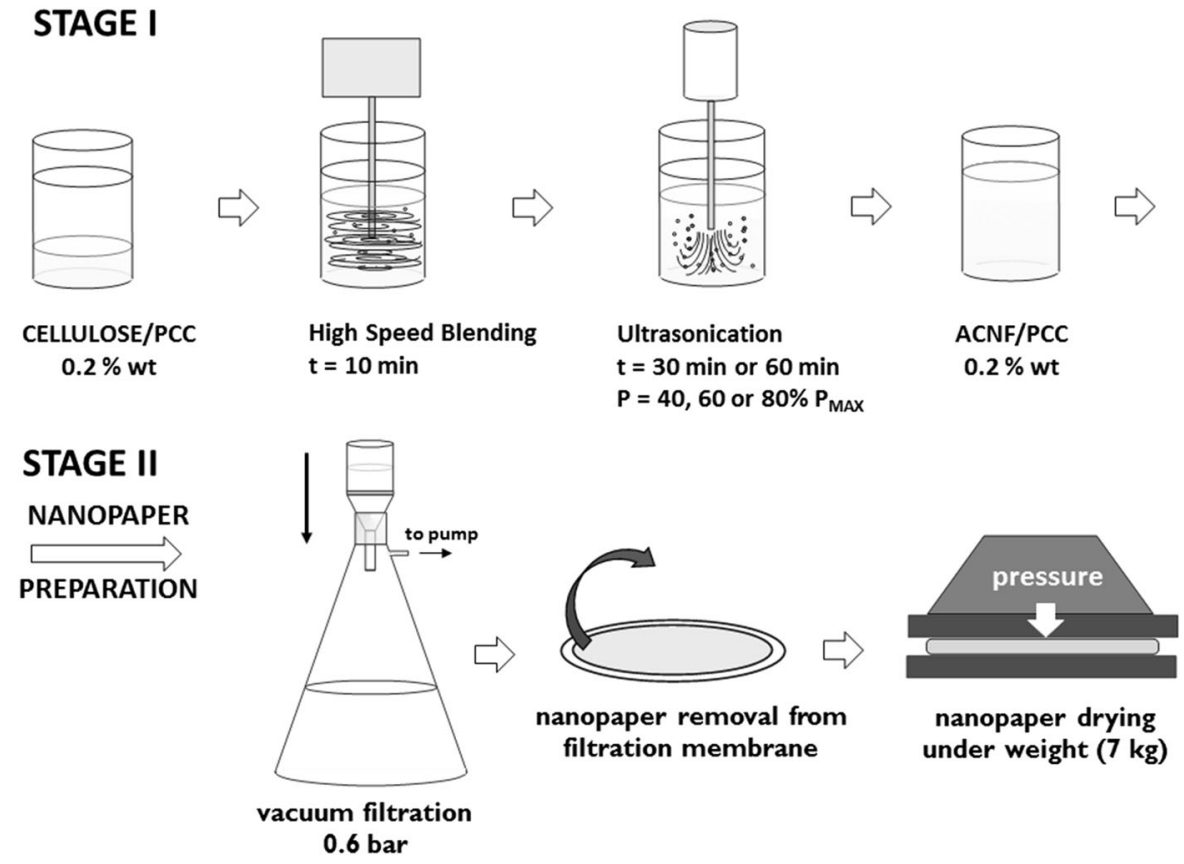

obtained on Omnic Software (ThermoScientific, Waltham, MA, USA).

$X$-ray diffractometry $(X R D)$

Through the process of cellulose isolation the precipitated calcium carbonate (PCC) was deposited on cellulose fibers. The calcium carbonate content was determined as $\mathrm{Ca}$ content in control sample using Flame Atomic Absorption Spectroscopy (FAAS, Varian SpektrAA 280-FS).

\section{FTIR analysis}

FT-IR spectra were collected on Nicolet 6700 Fourier Transform infrared spectrometer (FTIR, ThermoScientific, Waltham, MA, USA). The Smart iTR ATR sampling accessory was used. The nanopapers were directly placed on ATR crystal and measured. The spectra were collected over the range $4000-650 \mathrm{~cm}^{-1}$. For each material, 5 samples under the same conditions were examined. For each sample, 200 scans were averaged with spectral resolution $4 \mathrm{~cm}^{-1}$. Then for a given material, final average spectrum was calculated. These spectra were normalized to 1.0 at $1030 \mathrm{~cm}^{-1}$ (COH stretching vibration). Baseline corrections were
Degree of crystallinity was determined by means of the X-ray diffraction (XRD) method. All samples were lyophilized before measurements. The X-ray diffractometer Empyrean (PANalytical, The Netherlands) was used. Samples were scanned with $\mathrm{Cu} \mathrm{K} \alpha$ radiation $(\lambda=0.15418 \mathrm{~nm})$. The parameters of the working lamp were as follows: $\mathrm{U}=40 \mathrm{kV}, \mathrm{I}=25 \mathrm{~mA}$. The intensity of reflections was measured over the angular $5^{\circ}-90^{\circ} 2 \theta$ with step intervals of $0.05^{\circ}$. The duration of the reflection count was $10 \mathrm{~s}$. The crystalline phase composition and degree of crystallinity was calculated due to the Polish Standard PN-EN 13925-1:2007 based on amorphous subtraction method (Ahvenainen et al. 2016). Briefly, the CI [\%] of a sample is defined by the intensity ratio of the diffraction peaks and of the sum of all measured intensity. But even a completely crystalline sample has some background intensity, which arises from the X-ray optics of the instrument, sample fluorescence and scatter. This constant background intensity is subtracted from the total intensity which is sum of signals coming from crystalline lattices, amorphous parts of sample and finally from 
background. Therefore, the crystallinity degree is calculated from the given equation:

$\mathrm{CI} \%=\frac{\mathrm{I}_{\mathrm{C}}}{\mathrm{I}_{\mathrm{C}}+\mathrm{I}_{A}} \cdot 100 \%$,

where $I_{C}$-is the intensity of all reflection from crystalline phases, $\mathrm{I}_{\mathrm{A}}$-is the total intensity of amorphous phases.

Additionally, the crystallinity index and crystallite size of pure apple cellulose (isolated in distilled water) was evaluated by XRD method. The average thickness of cellulose crystallites was estimated from the X-ray diffraction patterns by using Scherrer's equation $\mathrm{D}_{\mathrm{hk} 1}=\mathrm{K} \lambda / \mathrm{FWHM} \cos \theta$, where $\mathrm{D}_{\mathrm{hk} 1}$ is the crystallite dimension in the direction normal to the hkl lattice planes, $\mathrm{K}$ is the correction factor and usually taken to be $0.9, \lambda$ is the radiation wavelength, $\theta$ is the Bragg angle corresponding to the (200) plane at $22^{\circ}$ and FWHM is the peak width at half maximum intensity measured at the (200) plane (French 2014).

\section{Scanning electron microscopy (SEM)}

Morphology of ACNF/PCC nanopapers surface was examined by scanning electron microscope (SEM, Hitachi SU3500) operate at $1.5 \mathrm{kV}$ in high vacuum conditions. The small cuts of each sample was applied on aluminum stage covered by carbon tape. Then the samples were coated with an ultrathin $(\sim 1 \mathrm{~nm})$ layer of gold layer $(\mathrm{Au})$ in an ion sputtering machine (Cressington Sputter Coater 108 Auto).

\section{Atomic force microscopy (AFM)}

The ACNF/PCC was suspended in ultrapure water (Millipore) to obtain the $0.1 \% \mathrm{wt}$ concentration. Then suspension was deposited onto a microscopic slide and dried in room temperature at $23{ }^{\circ} \mathrm{C}$ for $24 \mathrm{~h}$. The samples were kept in a desiccator before AFM observations. Bioscope Catalyst II, supported with Nanoscope V controller (Bruker, Billerica, MA, USA) was used for imaging in the ScanAsyst mode. A silicon nitride cantilever (Bruker) with nominal radius of pyramidal tip $2 \mathrm{~nm}$, spring constant of $0.4 \mathrm{~N} \mathrm{~m}^{-1}$ and resonance frequency of $70 \mathrm{kHz}$ was used. Scanning settings were: scan area $4 \mu^{2}$ (aspect ratio $1: 1$ ), image resolution $512 \times 512$, scan rate $0.5 \mathrm{~Hz}$. For each sample, around 12 topographic images of the surface from various regions were collected.
Rheological properties of ACNF/PCC dispersions

Rheological properties of cellulose/PCC aqueous dispersions were evaluated using an R/S Plus rheometer (Brookfield, Middleboro, MA) with coaxial cylinders with double gap DG 22.75/23.50 (bob in cup type) sensor. Measurements were performed at $20 \pm 0.5^{\circ} \mathrm{C}$ at constant shear rate $\left(50 \mathrm{~s}^{-1}\right)$ for the estimation of viscosity and at variable shear rate (50$500 \mathrm{~s}^{-1} ; 500-50 \mathrm{~s}^{-1}$ ) for the estimation of flow curves. In order to estimate the thixotropic effect, the surface area of the hysteresis loop between the upward flow curve (shear rate increased from 50 to $500 \mathrm{~s}^{-1}$ ) and the downward flow curve (shear rate decreased from 500 to $50 \mathrm{~s}^{-1}$ ) was determined (Dolz et al. 2007). The Power Law Equation, also called the Ostwald de Wael model, was used to describe the experimental flow curves and was given by:

$\tau=K \dot{\gamma}^{n}$

where $\tau$-shear stress (Pa), $\mathrm{K}$-consistency index (Pa $\left.\mathrm{s}^{\mathrm{n}}\right), \dot{\gamma}$ - the shear rate $\left(\mathrm{s}^{-1}\right), \mathrm{n}$-flow behavior index. The Ostwald-de Wael model typically describes Newtonian fluids for $n=1$ (Eq. 1). Whereas $n<1$ describes the pseudoplastic behavior and $n>1-$ dilatant fluid. The more n-value departs from 1 the greater deviation from Newtonian flow is. The consistency index $\mathrm{K}$ taken from Ostwald-de Wael model can be related to the viscosity of samples i.e. the higher $\mathrm{K}$ values, the higher viscosity.

\section{Zeta potential and particle size of ACNF/PCC dispersions}

Set of ACNF/PCC dispersions $(0.2 \%)$ were diluted with Milli-Q water to obtain the solid phase concentration of $0.1 \%$. Next, the $1.5 \mathrm{~mL}$ of each was dosed (in triplicate) to polystyrene cuvettes possessing the caps. To investigate the stability in time of obtained ACNF/PCC dispersions the six series of samples were prepared (for 0, 2, 4, 7, 30 and 60 days, respectively) and kept in dark at ambient temperature $\left(21 \pm 1{ }^{\circ} \mathrm{C}\right)$ before measurements. The loss of water $( \pm 0.0001 \mathrm{~g})$ from samples during their storage in closed cuvettes was determined gravimetrically (ONYX OX-220 scale, FAWAG, Lublin, Poland). It was performed in nine repetitions for each sample. Knowing the initial content of solid phase, the percentage concentration by weight $(\mathrm{C} \%)$ was calculated. 
The mean hydrodynamic diameter $\left(\mathrm{d}_{\mathrm{h}}\right)$ of particles dispersed in water was obtained using Dynamic Light Scattering (DLS) method (ISO 13321 1996; Kaszuba et al. 2008). Measurements were performed by means of Zetasizer Nano ZS (Malvern Instruments Ltd., Malvern, UK) apparatus (633 nm He-Ne laser light; $173^{\circ}$ detection angle in Non-Invasive Back-Scatter technique) at $20^{\circ} \mathrm{C}$. Each measurement was composed of twelve sub-runs and a multiple narrow mode was applied for the data analysis. Only the fresh samples ( 0 day) were mixed before measurements, the others (stored in time) were in static state. Heterogeneity of samples regarding to the particles size was described by polydispersity index (PDI) and the lower PDI value, the more uniform system (ISO 13321 1996).

The relative hydrodynamic diameter $\left(\mathrm{Rd}_{\mathrm{h}}\right)$ defined by Eq. 2 was used to show the particles size changes during the storage:

$R d_{h}=\frac{d_{h, i}}{d_{h, 0}}$

where $d_{h, i}$ is the mean hydrodynamic diameter after $\mathrm{i}$-days of samples storage and $\mathrm{d}_{\mathrm{h}, 0}$ is the mean hydrodynamic diameter of particles in fresh samples (0 day).

The Laser Doppler Electrophoresis was applied to determine electrophoretic mobility (EM) of particles dispersed in water (Mayinger 1994). Measurements were carried out using Zetasizer Nano ZS equipment and dip cell in nine repetitions (12 sub-runs per measurement) at $20{ }^{\circ} \mathrm{C}$. In a general purpose model used by the apparatus software the electrolytic conductivity (EC) was determined simultaneously with EM. Basing on the EM values the zeta potential (ZP) was calculated using the Henry's equation with the Smoluchowski approximation (Delgado et al. 2007).

\section{Mechanical properties of ACNF/PCC nanopapers}

Dry samples of ACNF/PCC composites were prepared as rectangular strips, with length of $40 \mathrm{~mm}$ and width of approx. $5 \mathrm{~mm}$. Precise measurements of each sample width was carried out before the test using Olympus SZX16 microscope (Olympus Corporation, Japan) with SDF PLAPO 0.5 XPF lens, equipped with Canon Power Shot A640 digital camera (Canon Inc.,
Japan). Image resolution was equal to $6.57 \mu \mathrm{m}$ per pixel. The width of each sample was calculated as the mean value from three measurements. The thickness of each sample was measured using digital micrometer BAKER IP54 (Baker Gauges India Private Limited, India) with measurement accuracy equal to $0.001 \mathrm{~mm}$. ACNF/PCC composites strips were subjected to uniaxial tensile testing using a miniature tensile stage (Deben Microtest, Suffolk, UK). The initial gap between grips was equal to $4 \mathrm{~mm}$. Mechanical experiments were carried out up to a strain of $50 \%$ with a deformation speed of $1.0 \mathrm{~mm} / \mathrm{min}$. Tensile force and elongation of the sample were recorded and converted into stress and strain respectively. The stress was determined as the ratio of tensile force to the samples cross sectional area. The strain was defined as the ratio of the sample elongation to its initial length. The Young's modulus was determined as the slope of the longest linear part of the stress-strain curve. For each composite mechanical test was carried out in ten replications.

\section{Statistical analysis}

Multi-factor ANOVA (Statistica v. 12, StatSoft, Cracow, Poland) was performed to evaluate the influence of the ultrasonication (the action time and power) and samples stored by 60 days on the obtained results at 0.05 significance level. The post hoc Tukey test was done to find the significantly different data.

\section{Results}

Structural evaluation of ACNF/PCC nanopapers

The FTIR spectra were obtained for cellulose with PCC before and after the ultrasound treatment (Fig. 2). Additionally, as the Supplementary Material FTIR spectrum of lime stone from the tap water precipitated by evaporation is presented (see Supplementary materials: Fig. S1). All bands visible there can be associated with crystalline forms of calcium carbonate (Cizer et al. 2012; Klinkaewnarong and Utara 2018; Vagenas et al. 2003). The FTIR spectra can serve also as the indicator of the isolation performance and the proof that other polysaccharides were removed during the isolation (Szymańska-Chargot et al. 2017). The FTIR spectrum contained mostly 
Fig. 2 FTIR spectra of cellulose isolated from apple before (M0t0) and after use of ultrasonication (M40t30, M40t60, M60t30, M60t60, M80t30 and M80t60)

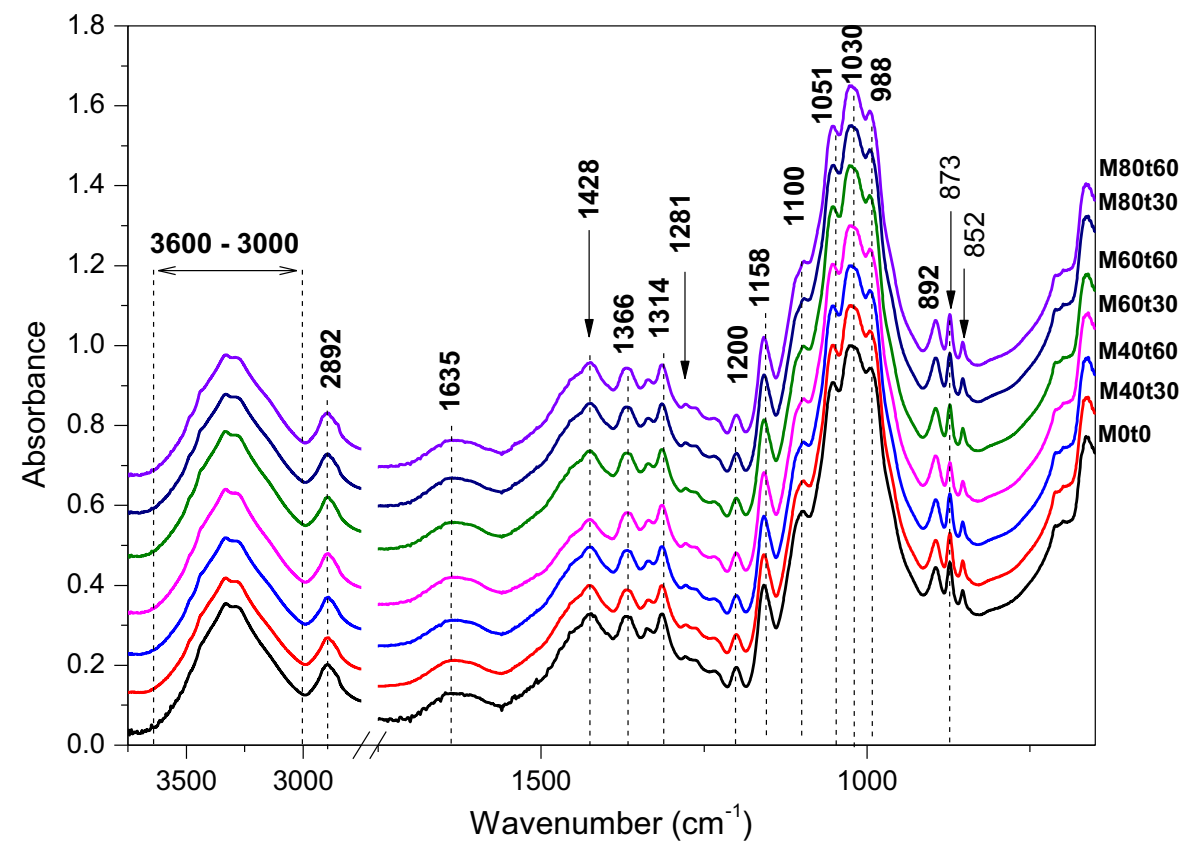

the cellulose bands. The broad band at $1635 \mathrm{~cm}^{-1}$ originated from bounded water (Szymańska-Chargot and Zdunek 2013). The region $1500-650 \mathrm{~cm}^{-1}$ is particularly sensitive for stretching vibrations of $\mathrm{C}-\mathrm{O}$, $\mathrm{C}-\mathrm{C}$, ring structures, deformation vibrations of $\mathrm{CH}_{2-}$ $\mathrm{OH}$ groups. The band at $1282 \mathrm{~cm}^{-1}$ is most probably associated with $\mathrm{CH}$ bending vibration ( $\mathrm{Li}$ and Renneckar 2011). The bands at $1158 \mathrm{~cm}^{-1}$ and $1200 \mathrm{~cm}^{-1}$ are related to $\mathrm{C}-\mathrm{O}-\mathrm{C}$ asymmetric and symmetric stretching vibration of glycosidic linkage, respectively (Kačurakova et al. 2002). The strongest bands were those related to the $\mathrm{C}-\mathrm{C}, \mathrm{C}-\mathrm{OH}$ and $\mathrm{C}-\mathrm{H}$ ring and side group stretching vibrations at 1051, 1030 and $988 \mathrm{~cm}^{-1}$ (Kačurakova et al. 2002; Fan et al. 2012). The band between $3000-2800$ is related to vibration of $\mathrm{CH}_{2}$ and $\mathrm{CH}_{2} \mathrm{OH}$ groups, while braod band from 3600 to $3000 \mathrm{~cm}^{1}$ is related to $\mathrm{OH}$ vibrations ( $\mathrm{Li}$ and Renneckar 2011). The most characteristic bands typical for cellulose can be found at 1030 and at $892 \mathrm{~cm}^{-1}$ assigned to $\mathrm{C}-\mathrm{O}$ stretching vibration and the glycosidic- $\mathrm{C}_{1} \mathrm{H}$ deformation, respectively (Jiang and Hsieh 2015). These bands can serve as the indicators of the cellulose presence in the composite (Chylinska et al. 2016; Szymańska-Chargot et al. 2015). But also additional bands at 873 and $852 \mathrm{~cm}^{-1}$ are visible and a significant broadening of bands in the range of $1300-1500 \mathrm{~cm}^{-1}$ (Fig. 2). These bands are associated with a carbonate out-of-plane bending $\left(v_{2}\right.$ mode) vibration in calcium carbonate which is active for all the three polymorphs of calcium carbonate. For aragonite, this vibration appears at ca. $855 \mathrm{~cm}^{-1}$, whereas for calcite and vaterite crystals, the positions of the corresponding $v_{2}$ vibrations are very similar and appear at about $875 \mathrm{~cm}^{-1}$ (Cizer et al. 2012; Guo et al. 2011; Klinkaewnarong and Utara 2018; Stoica-Guzun et al. 2012; Vagenas et al. 2003). In the present case, a sharp peaks at 873 and $852 \mathrm{~cm}^{-1}$ on all spectra as in Fig. 2 confirm that calcium carbonate was precipitated on cellulose in all three crystalline phases: calcite, vaterite and aragonite.

The relative crystallinity of ACNF/PCC before and after ultrasonication was determined using XRD diffractograms (Table 1). The crystallinity index of

Table 1 Crystallinity degree of ACNF/PCC composites

\begin{tabular}{ll}
\hline Sample & Crystallinity degree $(\%)$ \\
\hline M0t0 & $63.68( \pm 9.35)$ \\
M40t30 & $57.91( \pm 10.23)$ \\
M40t60 & $57.81( \pm 10.38)$ \\
M60t30 & $57.09( \pm 10.39)$ \\
M60t60 & $50.72( \pm 10.65)$ \\
M80t30 & $51.75( \pm 10.39)$ \\
M80t60 & $52.55( \pm 10.45)$ \\
\hline
\end{tabular}


pure apple cellulose was $51.34 \%$ and crystallite size was $2.28 \mathrm{~nm}$. The phase analysis of XRD diffraction pattern also confirmed the presence of calcium carbonate in the composites. In the case of unprocessed cellulose/PCC (M0t0) crystallinity index was $63.68 \%$. Whereas for ACNF/PCC processed for $30 \mathrm{~min}$ of ultrasound treatment the crystallinity degree was around $57-58 \%$, regardless the ultrasound power. The increasing of the ultrasound treatment time to 60 min caused decrease of crystallinity indexes to the $50-52 \%$.

Influence of ultrasounds on morphology of ACNF/ PCC nanopapers

Figure 3 presents the AFM images of cellulose fibers before (Fig. 3a) and after use of ultrasonication (Fig. 3b-g). AFM imaging was conducted on cellulose dispersions in water, not on nanopapers. The microfibrils as well as macrofibrils are visible in images of cellulose isolated from apple pomace (Fig. 3a). However, it should be also stated that the cellulose isolated from apple itself is very thin (Szymańska-Chargot et al. 2017). The usage of ultrasonication apparently disintegrated the cellulose into nanofibrils. Only in the case of M80t60 sample the visible swelling of microfibrils occurred, which can suggests that the fibers surface can be changed into amorphous forms of cellulose with higher water holding capacity. Even though, it can be assumed that ultrasonic treatment is effective in fibrillating the cellulose microfibrils into nanofibrils regardless the ultrasonication power or time.

The morphological characteristic of vaccum-filtrated ACNF/PCC nanopapers prepared via different ultrasonication conditions were compared with SEM images (Fig. 4). Crystals of calcium carbonate with diameter around $1 \mu \mathrm{m}$ forming irregular spherical shapes was observed onto the surface of nanopaper obtained for control sample M0t0 (Fig. 4a). The M40t30 sample comparing with the control sample seems to be quite homogeneous, however some rods of $\mathrm{CaCO}_{3}$ are present as well (Fig. 4b). In the case of application of higher ultrasonication power (M60t30) apart of rods the small spherical particles appeared (Fig. 4c). In the case of sample M80t30 a lot of rods with sharp edges and scattered length appeared. The prolongation of ultrasonication time for each power values caused the occurrence of some cubic forms and rods as well as a lot of small spherical particles (Fig. $4 \mathrm{e}-\mathrm{g}$ ).
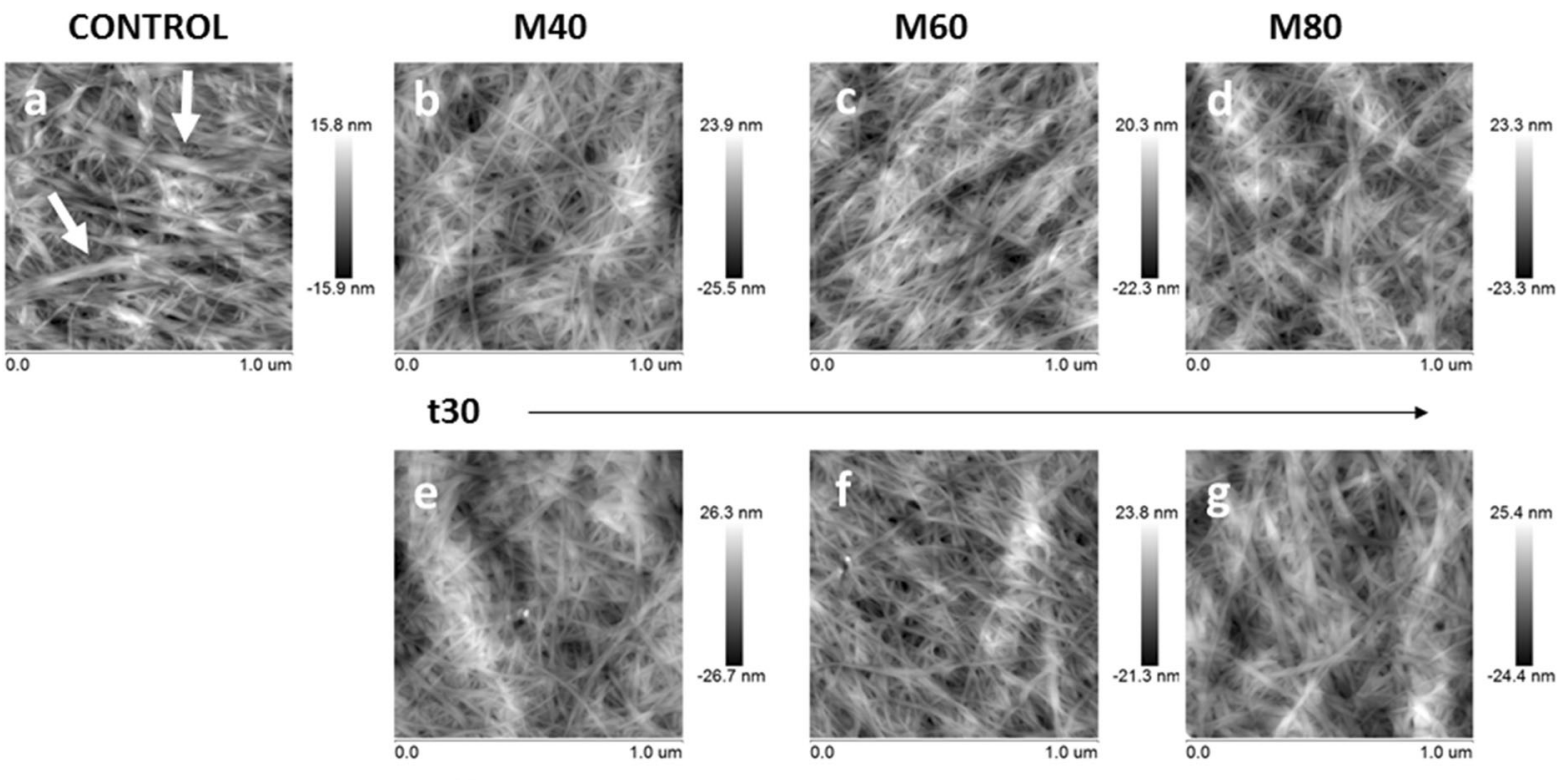

$25.4 \mathrm{~nm}$

t60

Fig. 3 Representative AFM height images of cellulose isolated from apple before (a) and after use of ultrasonication (b-g). The images a, e presents the nanofibers after use of $40 \%$ of maximum ultrasonicator power, c, f $60 \%$, and $\mathbf{d}, \mathbf{g} 80 \%$ after 30 and $60 \mathrm{~min}$ treatment, respectively. The cellulose macrofibrils are indicated with white arrow 


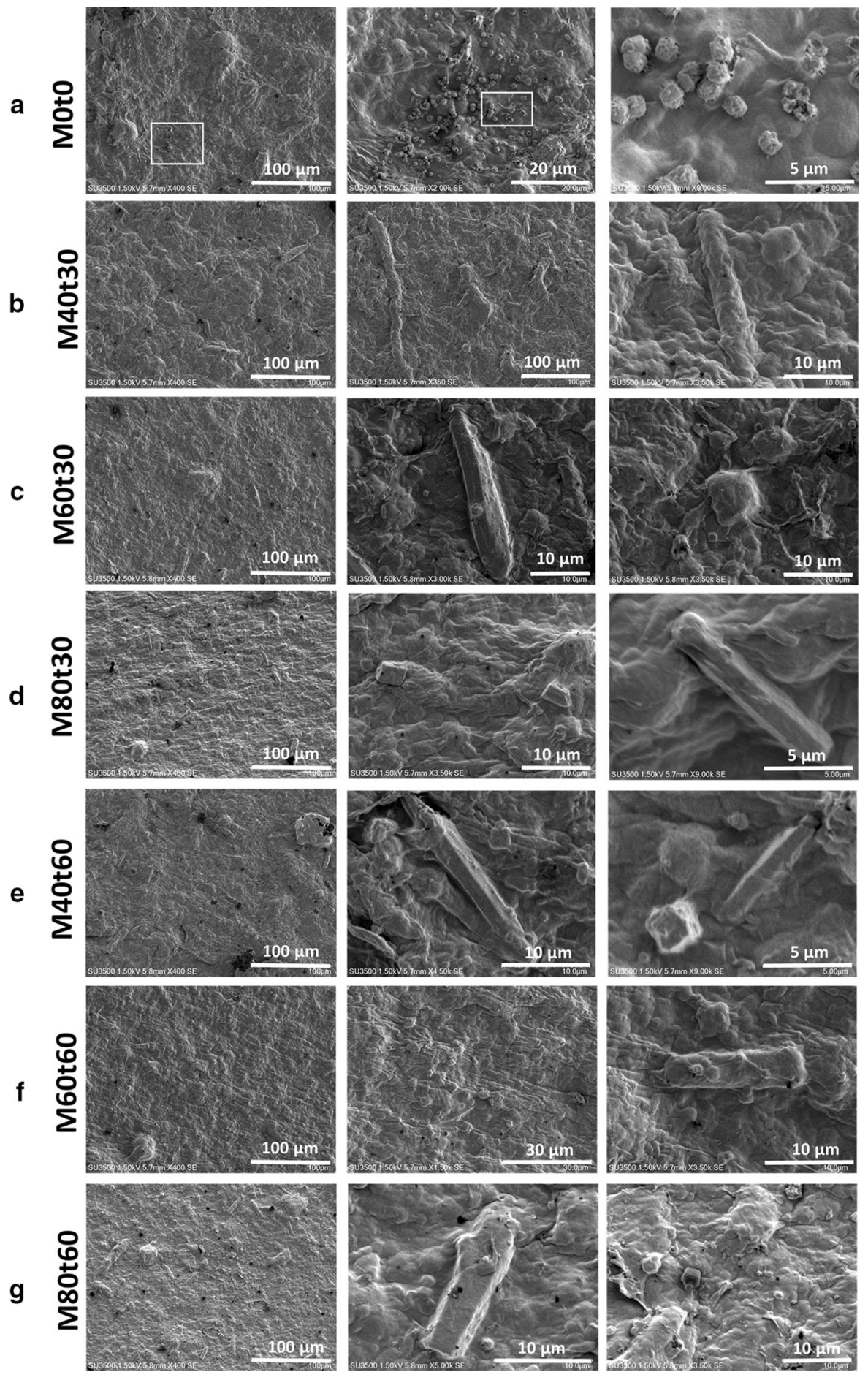

Fig. 4 SEM images of ACNF/PCC nanopapers before $(\mathbf{a})$ and after $(\mathbf{b}-\mathbf{g})$ ultrasonication. The images $\mathbf{b}, \mathbf{e}$ presents the nanofibers after use of $40 \%$ of maximum ultrasonicator power, c, f $60 \%$, and $\mathbf{d}, \mathbf{g} 80 \%$ after 30 and 60 min treatment, respectively 
Rheological properties of different ACNF/PCC suspensions

The flow curves (shear stress vs. shear rate, not presented) for the suspensions were obtained within the range of $50-500 \mathrm{~s}^{-1}$. Table 2 presents the parameter of the Ostwald-de Wael models for the flow curves. In both cases the goodness of fit described by $\mathrm{R}^{2}$ was high and above of 0.9 . In both ascendant and descendant curves the goodness of fit $\left(\mathrm{R}^{2}\right)$ was above 0.9. Based on the model all suspensions can be classified as pseudoplastic due to $\mathrm{n}<1$.

The thixotropic effect was also calculated for samples. Thixotropic is reversible effect of decreasing of viscosity with the time of shearing. The thixotropic effect is estimated as surface area of hysteresis loop between ascendant and descendant curve (Hubbe et al. 2017a). The physical meaning of thixotropic effect is the fluid transition from gel to sol during application of force (shear stress), but as the process is reversible the fluid return to gel state after withdrawing the force (Mierczyńska et al. 2017). Generally, thixotropic effect was low for all samples reaching values from 7.40 to $168.62 \mathrm{~Pa} \mathrm{~s}^{-1}$, with the lowest value obtained for the control sample (M0t0). After application of ultrasounds the thixotropic effect considerably increased, however, the highest value was obtained for the lowest applied power (M40t30 and M40t60). Further increase of the ultrasound power caused decrease of thixotropic properties. Moreover, time of ultrasound treatment caused further slight decrease in thixotropic effect.

The lowest consistency index $\mathrm{K}$ was obtained for control samples (M0t0) and this sample had also the lowest viscosity close to 0 (Fig. 5a). For all samples $\mathrm{K}$ was lower than 0.5 . The only differed sample was M40t30 for which K was 1.70. Nevertheless, the most samples exhibited the pseudoplastic behavior with quite low viscosity. The viscosity of analyzed suspensions is presented in Fig. 5a. The lowest viscosity was $0.003 \mathrm{~Pa} \cdot \mathrm{s}$ (M0t0), which is similar to the viscosity obtained for pure water (Mierczyńska et al. 2017). The highest viscosity was obtained for the sample M40t30 and it was $0.0618 \mathrm{~Pa}$ s when sample was subjected for ultrasound for $30 \mathrm{~min}$. Then, increase of power caused decrease of viscosity to the level of $0.02-0.03 \mathrm{~Pa} \mathrm{~s}$ regardless time of exposure. At certain power, a clear effect of time was noted only for samples treated with the lowest power of ultrasounds (M40). The Fig. 5b presents viscosity of the samples as function of shear rate in the chosen range of 50-500 $\mathrm{s}^{-1}$. All ultrasonicated samples presented the same trend of hyperbolic decrease in the viscosity as the shear rate increased. Around $300 \mathrm{~s}^{-1}$ all viscosity functions reach plateau of 0.007-0.008 Pa s.

Particles size and electrokinetic properties

Results obtained for the ACNF/PCC samples prepared using different power and time of ultrasound treatment, are shown in Fig. 6.

The mean hydrodynamic diameter of particles in the M0t0 sample was about $9900 \pm 1700 \mathrm{~nm}$ (Fig. 6a). The $60 \mathrm{~min}$ ultrasound treatment led to decrease of particles size to about $4000 \mathrm{~nm}$ in all systems. At the same time, the increase of sonication power from 40 to $80 \%$ did not affect the hydrodynamic diameter significantly. Short time of sonication as well
Table 2 The Ostwald-de Wael model parameters describing rheological properties of $\mathrm{ACNF} / \mathrm{PCC}$ suspensions after ultrasonication

$\mathrm{K}$ - flow consistency index, $\mathrm{n}$-flow behavior index, $\mathrm{R}^{2}$ - goodness of fitting

\begin{tabular}{|c|c|c|c|c|c|c|}
\hline \multicolumn{7}{|c|}{ Ostwald-de Wael model } \\
\hline \multirow[t]{2}{*}{ Sample } & \multicolumn{3}{|c|}{ Ascendant curve } & \multicolumn{3}{|c|}{ Descendant curve } \\
\hline & $\begin{array}{l}\mathrm{K} \\
\mathrm{Pa} \mathrm{s}{ }^{\mathrm{n}}\end{array}$ & $\begin{array}{l}\mathrm{n} \\
-\end{array}$ & $\begin{array}{l}\mathrm{R}^{2} \\
-\end{array}$ & $\begin{array}{l}\mathrm{K} \\
\mathrm{Pa} \mathrm{s}{ }^{\mathrm{n}}\end{array}$ & $\begin{array}{l}\mathrm{n} \\
-\end{array}$ & $\begin{array}{l}\mathrm{R}^{2} \\
-\end{array}$ \\
\hline M0t0 & $0.01( \pm 0.00)$ & $0.84( \pm 0.07)$ & 0.9990 & $0.00( \pm 0.00)$ & $0.88( \pm 0.02)$ & 0.9991 \\
\hline M40t30 & $1.70( \pm 0.26)$ & $0.10( \pm 0.02)$ & 0.6432 & $0.43( \pm 0.16)$ & $0.33( \pm 0.06)$ & 0.8615 \\
\hline M60t30 & $0.25( \pm 0.13)$ & $0.43( \pm 0.08)$ & 0.9796 & $0.07( \pm 0.02)$ & $0.60( \pm 0.03)$ & 0.9861 \\
\hline M80t30 & $0.47( \pm 0.22)$ & $0.33( \pm 0.07)$ & 0.9557 & $0.15( \pm 0.06)$ & $0.50( \pm 0.05)$ & 0.9684 \\
\hline M40t60 & $0.54( \pm 0.10)$ & $0.28( \pm 0.03)$ & 0.9652 & $0.12( \pm 0.03)$ & $0.52( \pm 0.04)$ & 0.9677 \\
\hline M60t60 & $0.36( \pm 0.11)$ & $0.37( \pm 0.05)$ & 0.9838 & $0.12( \pm 0.03)$ & $0.53( \pm 0.03)$ & 0.9786 \\
\hline M80t60 & $0.26( \pm 0.05)$ & $0.41( \pm 0.03)$ & 0.9933 & $0.10( \pm 0.01)$ & $0.56( \pm 0.02)$ & 0.9902 \\
\hline
\end{tabular}



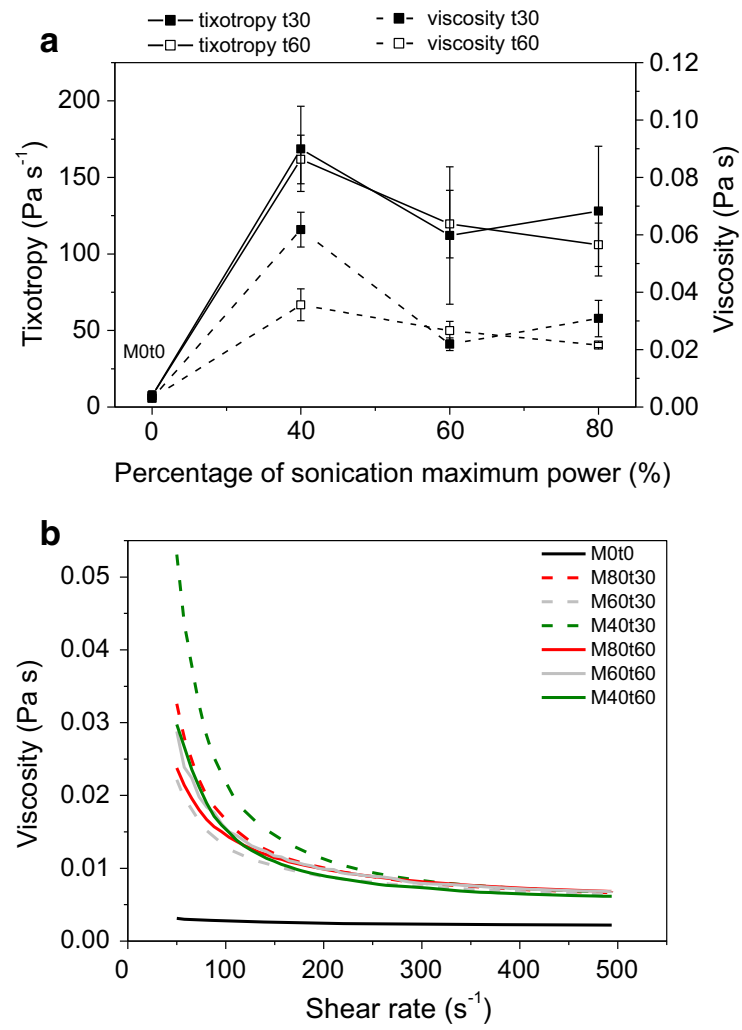

Fig. 5 a The thixotropic effect (solid line) and viscosity (dashed line) obtained as the function of used sonication power for $\mathrm{t}=30 \mathrm{~min}$ (full square) and $\mathrm{t}=60 \mathrm{~min}$ (empty square); b dynamic viscosity as a function of the shear rate $\left(50-500 \mathrm{~s}^{-1}\right)$

as the applied lower power did not change the hydrodynamic diameter significantly (size ranged from $6900 \pm 1300$ to $9000 \pm 100 \mathrm{~nm}$ for M40t30 and M60t30, respectively). In the case of the 30-min ultrasounds action the smallest particles $(5000 \pm 700 \mathrm{~nm})$ were obtained at the highest power of sonication (M80t30).

As it can be seen in Fig. 6b, the control sample was quite uniform (PDI equaled $0.5 \pm 0.3$ ) but application of ultrasounds even for only $30 \mathrm{~min}$ led to obtain highly heterogeneous samples (PDI about 1.0 for all ultrasound powers). It indicates, that the new classes of particles were generated during sonication. However, the number of these particles was not sufficient to affect the value of mean hydrodynamic diameter. Uniform systems in terms of the particles size (PDI about 0.6 ) were obtain as a result of $60 \mathrm{~min}$ ultrasound treatment regardless the powers.

The ACNF/PCC dispersions were characterized by the negative values of electrophoretic mobility and zeta potential (Fig. 6). The absolute values of these parameters were the lowest for the control sample $(0.82 \pm 0.08 \mu \mathrm{m} \mathrm{cm} / \mathrm{Vs}$ for $\mathrm{EM}$ and $11.52 \pm 1.10 \mathrm{mV}$ for $\mathrm{ZP})$. The application of ultrasounds led to obtaining more negative values of EM (about $-1.20 \mu \mathrm{m} \mathrm{cm} / \mathrm{Vs}$ ) and $\mathrm{ZP}$ (about $-17.00 \mathrm{mV}$ ). However, the extension of sonication time from 30 to $60 \mathrm{~min}$ as well as the increase of sonication power from 40 to $80 \mathrm{~W}$ did not affect both mentioned values. In terms of electrolytic conductivity values, only samples M40t60 and M80t60 differed from each (Fig. 6d).

The stability in time of ACNF/PCC dispersions

The ACNF/PCC dispersions were kept for 2 months in closed cuvettes (see Supplementary materials: Fig. S2). To determine the effect of storage on the particles size the ratio of mean hydrodynamic diameter $\left(\operatorname{Rd}_{h}\right)$ of stored sample to that of fresh one ( 0 day) was studied (Fig. 7). The period of samples storage $(p<0.001)$ affected $\mathrm{Rd}_{\mathrm{h}}$ values. For all the applied durations of ultrasonication the rapid increase of relative hydrodynamic diameter was observed during the first week of the samples storage. Further prolongation of storage time did not modify the $\mathrm{Rd}_{\mathrm{h}}$, in exception of sample which was treated by ultrasounds with the power of $40 \%$, for which the $\mathrm{Rd}_{\mathrm{h}}$ decrease in time was observed. The ultrasounds power used for the ACNF/PCC preparation also significantly $(p<0.001)$ influenced $\mathrm{Rd}_{\mathrm{h}}$. Generally, the relative mean hydrodynamic diameters of control sample (M0t0) were lower than those of ultrasounds-treated samples. This points that the ACNF/PCC particles show strong tendency to coagulate.

Both the electrophoretic mobility and zeta potential were affected by the initial preparation of samples (the duration time and ultrasound power) and the time of storage $(p<0.05)$. Generally, the absolute values of these electrokinetic parameters were higher for the 60-min sonicated samples and they increased with the increasing power of sonication (Fig. 7c, d). Within 7 days of storage the absolute values of EM and ZP decreased and for further days they were quite stable.

The loss of water occurring during the samples storage led to increase of the solid phase concentration in studied systems (Supplementraty material: Figs S3 $\mathrm{a}$ and b). The concentration was significantly $(p<0.001)$ affected by the storage time as well as 

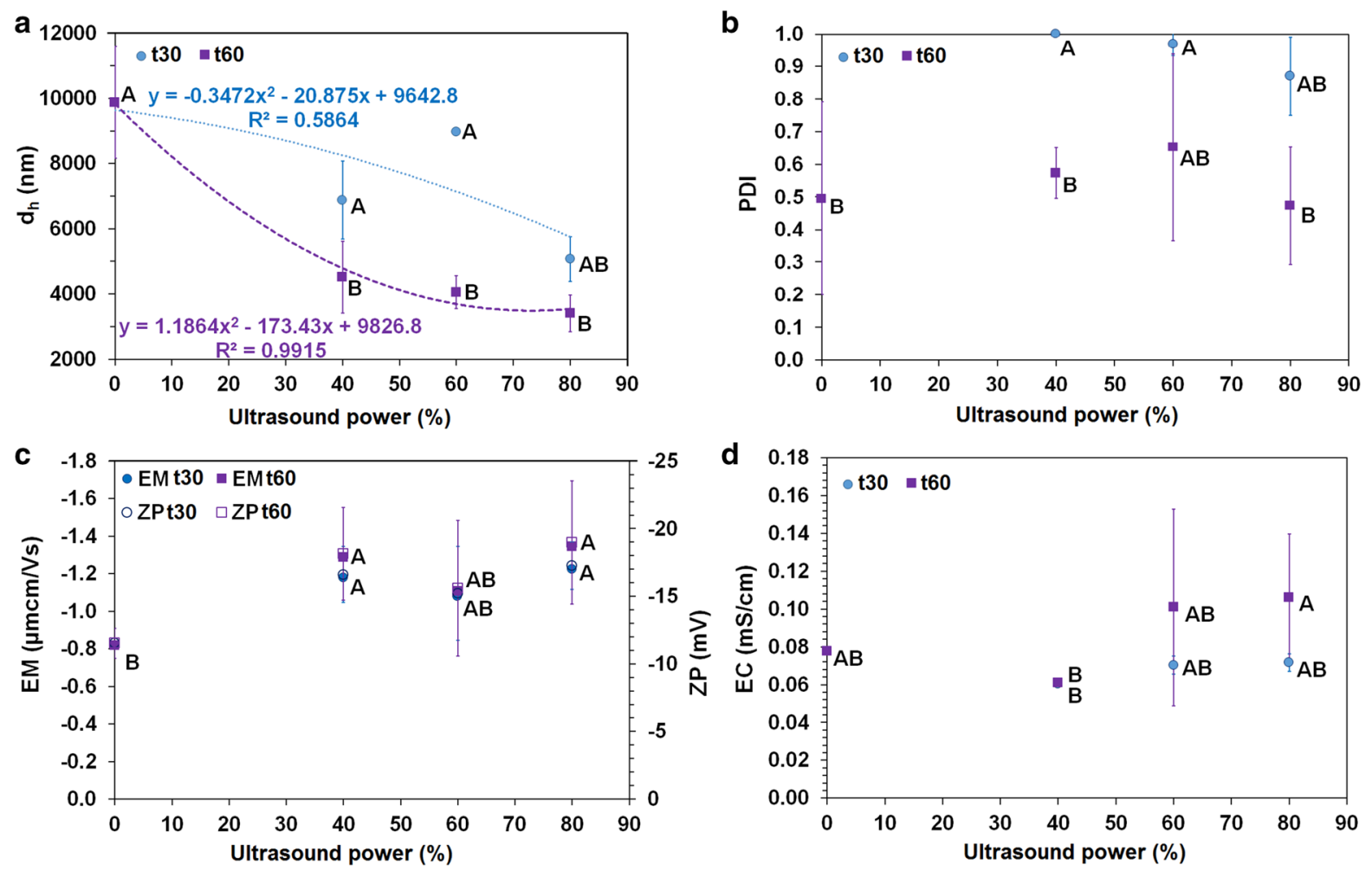

Fig. 6 Relationship between a mean hydrodynamic diameter, b polydispersity index, c electrophoretic mobility and zeta potential, d electrolytic conductivity, respectively, and

the time and power of ultrasonication. The ACNF/ PCC concentration increased insignificantly during the first week of samples storage. Further extension of time led to fast increase of samples concentration. As it can be seen, the longer ultrasonicated samples were less concentrated. The power of ultrasonication varied the results only in the case of 60 min treated samples and after 60 days of storage. The concentrations of samples previously affected by the power of 40 and $60 \% \mathrm{~s}$ were higher than those of others samples.

The electrolytic conductivity (EC) of samples was also affected by the time of storage $(p<0.001)$ and the ultrasound power $(p<0.01)$. During the 7 days of storage the EC values increased rapidly and for the next prolongation of storage time they obtained approximately constant value. Generally, the higher energy of ultrasounds was applied for the fresh samples ( 0 day), the lower EC values were detected during the samples storage.

The relationship between the samples concertation and EC (Supplementary material: Figs S3 c and d) can

ultrasound power; the bars reflect the standard deviation; different letters mean the significantly different results at $p<0.05$

be divide into two regions: with EC rapid increase and EC stabilized or decreased. The use of linear regression for these two parts of $\mathrm{EC}=\mathrm{f}(\mathrm{C} \%)$ dependence allowed to determine $\mathrm{C} \%$ values which correspond to the inflection points (Supplementary material: Table S1). These values were not significantly affected by the applied time of ultrasounds treatment but they decreased from 0.110 to $0.103 \%$ with the increase of the sonication power from 0 to $80 \%$.

Mechanical properties of nanopapers

The effect of ultrasonication power and time on mechanical properties of cellulose/PCC nanopapers is presented in Table 3. The elastic modules of the control sample was $2.25 \mathrm{GPa}$. The usage of ultrasound caused the increase of elastic modulus of nanopapers proportionally to the ultrasound power up to about $2.9 \mathrm{GPa}$. At a certain power, longer exposure to ultrasounds caused decrease of the nanopapers 

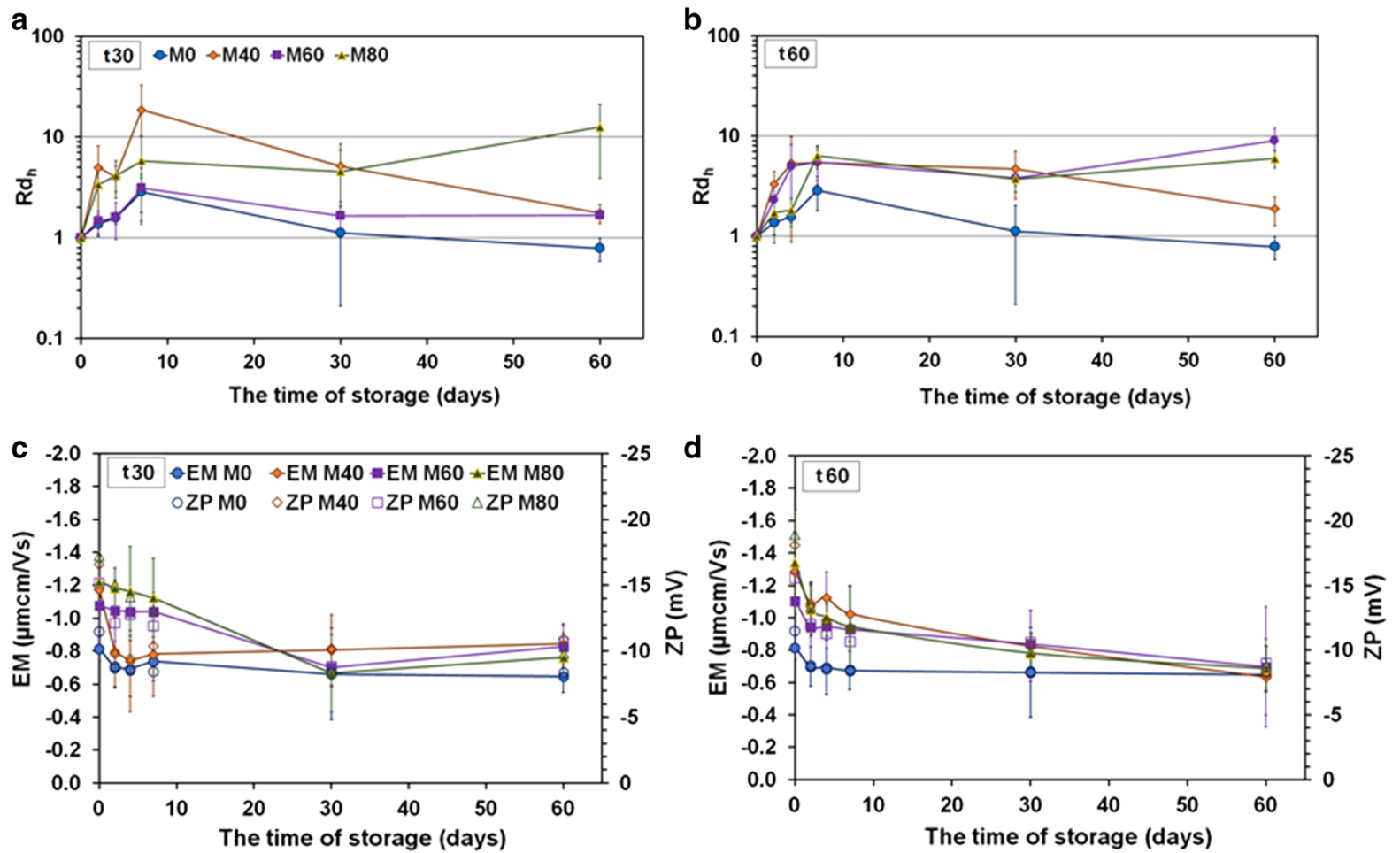

Fig. 7 Relative hydrodynamic diameter $\left(\mathrm{Rd}_{\mathrm{h}}\right)$ of particles in $\mathrm{ACNF} / \mathrm{PCC}$ dispersions $(\mathbf{a}, \mathbf{b})$ and electrophoretic mobility $(\mathrm{EM})$ and zeta potential (ZP) (c, d) during time of storage for the 30 and 60-min ultrasonicated ACNF/PCC dispersions

Table 3 Mechanical properties of ACNF/PCC nanopapers

Any two average values in the same column followed by the same superscript letter are not significantly different with $p>0.05$

\begin{tabular}{llll}
\hline Sample & $\begin{array}{l}\text { Elastic modulus } \\
\text { MPa }\end{array}$ & $\begin{array}{l}\text { Tensile strength } \\
\text { MPa }\end{array}$ & $\begin{array}{l}\text { Elongation at break } \\
-\end{array}$ \\
\hline M0t0 & $2250.1( \pm 384.1)^{\mathrm{A}}$ & $47.97( \pm 9.60)^{\mathrm{A}}$ & $0.05( \pm 0.01)^{\mathrm{A}}$ \\
M40t30 & $2847.2( \pm 502.9)^{\mathrm{B}, \mathrm{C}, \mathrm{D}}$ & $59.38( \pm 4.57)^{\mathrm{B}, \mathrm{C}}$ & $0.06( \pm 0.02)^{\mathrm{A}, \mathrm{B}}$ \\
M60t30 & $2914.4( \pm 408.5)^{\mathrm{B}, \mathrm{C}, \mathrm{D}}$ & $67.73( \pm 9.91)^{\mathrm{C}, \mathrm{D}}$ & $0.09( \pm 0.02)^{\mathrm{C}}$ \\
M80t30 & $3121.3( \pm 548.7)^{\mathrm{C}, \mathrm{D}}$ & $68.50( \pm 7.73)^{\mathrm{C}, \mathrm{D}}$ & $0.07( \pm 0.02)^{\mathrm{B}, \mathrm{C}}$ \\
M40t60 & $2436.8( \pm 338.6)^{\mathrm{A}, \mathrm{B}}$ & $59.23( \pm 8.64)^{\mathrm{B}, \mathrm{C}}$ & $0.08( \pm 0.02)^{\mathrm{B}, \mathrm{C}}$ \\
M60t60 & $2729.6( \pm 358.5)^{\mathrm{A}, \mathrm{B}, \mathrm{C}}$ & $69.70( \pm 4.65)^{\mathrm{D}}$ & $0.08( \pm 0.02)^{\mathrm{C}}$ \\
M80t60 & $2845.1( \pm 482.3)^{\mathrm{B}, \mathrm{C}, \mathrm{D}}$ & $59.41( \pm 7.79)^{\mathrm{B}, \mathrm{C}}$ & $0.06( \pm 0.01)^{\mathrm{A}}$ \\
\hline
\end{tabular}

stiffness however resulting elastic modulus was still higher for the each combination than the control sample.

The tensile strength of control sample was on the level of $47.97 \mathrm{MPa}$. The usage of ultrasound for 30 min caused increase of tensile strength of ACNF/ PCC nanopapers. The time of exposure to ultrasounds has various effects depending on the power used. Elongation of ultrasound time caused no change in tensile strength for M40 samples. The tensile strength of M80 decreased with time. M60 samples obtained greater tensile strength after $60 \mathrm{~min}$ of ultrasonication.

The elongation at break can be measure of nanopapers flexibility. The elongation at break has very low value for the each sample. The highest elongation at break had samples M60t30, M80t30, M40t60, M60t60, while the samples M40t30 and M80t60 were not statistically different from control sample (M0t0). 


\section{Discussion}

The nanocellulose/calcium carbonate composites are widely investigated in term of their use as hybrid composites. One of the method of the calcium carbonate incorporation onto cellulose micro- or nanofibrills is in situ precipitation (Dimic-Misic et al. 2016). Here, calcium carbonate was directly incorporated into cellulose fibrils during the process of cellulose isolation from plant material. The tap water used within research has a chemical composition typical of a reservoir of water produced mainly in carbonate rocks. Its average content of calcium carbonate is $334 \mathrm{mg} / \mathrm{L}$. The other trace elements are below $1 \mathrm{mg} / \mathrm{L}$ apart of magnesium which is $13.8 \mathrm{mg} / \mathrm{L}$ and chlorates which is $16.1 \mathrm{mg} / \mathrm{L}$ (Quarterly Water Quality Report 2017). According to Declet et al. (2016) the magnesium influences the calcium carbonate precipitation when the ratio $\mathrm{Mg}: \mathrm{Ca}$ exceeds 2:1 and here the amount of $\mathrm{Mg}$ ions was 24 times less than $\mathrm{Ca}$ ions. Moreover the FTIR spectrum of lime precipitated directly from tap water showed that it consists of calcium carbonate (Fig. S1). Apple pomace, often being waste after fruit processing, was used as the source of cellulose. The average content of calcium carbonate in composites was $3.74 \pm 1.36 \%$. The cellulose with precipitated calcium carbonate was introduced to ultrasound assisted homogenization to obtain the apple cellulose nanofibrils/precipitated calcium carbonate (ACNF/PCC) composites.

Physicochemical analyses showed pronounced effects of ultrasound treatment on the material at each step of nanopapers production. The AFM images showed that disintegration of cellulose fibers occurred during the ultrasound treatment (Fig. 3). Moreover, the increasing time or power of ultrasound treatment did not influence much the morphological characteristic of obtained nanofibrils. Chen et al. (2013) showed that usage of $1200 \mathrm{~W}$ of ultrasounds for $20 \mathrm{~min}$ on wood cellulose produced nanofibrils with average diameter below $12 \mathrm{~nm}$ (Chen et al. 2013). They also observed a slight decrease of cellulose crystallinity after ultrasound treatment. The same effect was observed in the case of investigations presented here (Table 1) - the crystallinity index of ACNF/PCC composites decreased after ultrasound treatment. However, usually the crystallinity index of cellulose after the use of ultrasound increases which is connected with the removal of amorphous part of cellulose and formation more crystalline nanocellulose (Chen et al. 2011a, b). On the other hand, this is the first time when the crystallinity index of cellulosecalcium carbonate composite after ultrasound treatment has been evaluated. For example Stoica-Guzun et al. (2012) presented only the XRD diffraction pattern of bacterial cellulose-precipitated calcium carbonate composites influenced by ultrasounds but it is hard to evaluate on this basis how the crystallinity index changed. However, recent studies of calcium carbonate addition during synthesis of bacterial cellulose showed that crystallinity degree decreased after addition of $\mathrm{CaCO}_{3}$ (Mohammadkazemi et al. 2016). Whereas, SEM images revealed that initially calcium carbonate was precipitated in form of spherical particles. While, introduction of the higher ultrasounds power and longer treatment time promoted the formation of cubical and rod-like structures of calcium carbonate crystals (Fig. 4). The rod- or needle- like structures are typical one of aragonite (Guo et al. 2011). Whereas, the spherical or cubic forms of calcium carbonate are typical for vaterite or calcite, respectively (Myśliwiec et al. 2016). The analysis of FTIR spectra suggests that the calcium carbonate crystallized in the form of calcite, vaterite or aragonite (Fig. 4). Abdel-Aal et al. (2002) showed that precipitation mechanism of $\mathrm{CaCO}_{3}$ has three steps: first formation of the amorphous phase, then formation of metastable phase (vaterite at low temperatures, aragonite at high temperatures), and finally transformation of metastable polymorphs into calcite. On the other hand Myśliwiec et al. (2016) showed that calcium carbonate crystallization induced by temperature and static magnetic field (here we used both during the cellulose isolation) can from either in metastable form of vaterite (mostly spherical forms) or thermodynamically stable calcite (cubic forms). Additionally in the case of the cellulose fibers or nanofibers presence during calcium carbonate precipitation the crystallization process is influenced by electrostatic interaction between cellulose and $\mathrm{CaCO}_{3}$ (Lu et al. 2017). In the case of sample M0t0 which wasn't introduced to the ultrasound process the mostly spherical forms were present. But the used of ultrasound induced the formation of cubic forms with tendency to aggregate which are more stable. According to Stoica-Guzun et al. (2012) in the case of calcium carbonate formation in bacterial cellulose the cellulosic matrix had protective function against ultrasounds which 
resulted in growing larger crystals (Stoica-Guzun et al. 2012).

The rheological properties of cellulose dispersions are usually determined by viscosity and thixotropic effect. The flow curves obtained for all dispersions according to Ostwald- de Wael model allowed to classify them as pseudoplastic fluids. Previously, the shear thinning of pure cellulose suspensions was obtained for cellulose isolated from sugar-beet pulp but also for microfibrillated cellulose suspensions (Dinand et al. 1996; Karppinen et al. 2012), nanofibrillated cellulose (Nechyporchuk et al. 2014) or cellulose whiskers (Azizi Samir et al. 2005; Bercea and Navard 2000). Moreover, addition of ions (calcium, chloride or sodium) reinforced the viscoelastic properties, but were not affected neither by temperature treatment nor by $\mathrm{pH}$ (Agoda-Tandjawa et al. 2010). Also, the addition of surfactants to CNF suspension enhanced the gelation properties even in low concentrations (Quennouz et al. 2016). Most recently, Maestri et al. (2017) have shown that application of ultrasounds breaks the TEMPO-oxidized cellulose fibrils in the amorphous region producing isolated nanofibrils which suspension forms weak but uniform and transparent gel (Maestri et al. 2017). This separation of fibrils avail the interaction of polymeric surface with water molecules effecting the rheological properties. In the very same paper the influence of multivalent cations addition on rheological properties of nanocellulose suspension was investigated. The conclusion driven is that cation valence promotes gel stiffness mediated by hydrogen interactions. Moreover, the sol-gel transition is induced both by ultrasounds and especially divalent cations presence. Liu et al. (2017) showed the $\mathrm{Ca}^{2+}$ ions coming from local dissolving the precipitated calcium carbonate can form the salt bridges on the surface of cellulose nanofibrills. Similar effect can be described in the case of ACNF/PCC dispersions presented here. The control sample (M0t0) did not exhibited any gel formation and has very low viscosity similar to water. The application of ultrasounds promoted the gel transition in the ACNF/PCC systems, however the viscosity of obtained dispersions was quite low (Fig. 5b).

The cellulose crystallites thickness studied by microscopy methods (in a dry state) is usually ranged from 3 to $70 \mathrm{~nm}$ at the length of few hundreds $\mathrm{nm}$ whereas for fibrillated nanocellulose the width of individual fibrils ranges from 20 to $30 \mathrm{~nm}$ (Hubbe et al. 2017b; Moberg et al. 2017). The particles size determined by DLS method for non-sonicated and the ultrasounds-treated nanocellulose/PCC sols (Fig. 6a) was much higher than the above mentioned. It resulted from the presence of hydration layer around the particles dispersed in water, presence of precipitated calcium carbonate as well as the difference between real shape of nanocellulose/PCC complex particles and the spherical shape established in this method for hypothetical particle with the same diffusion coefficient as the investigated particle (ISO 13321 1996; Yadav et al. 2017). Presence of non-regular-shaped nanofibrills in the all studied samples could lead to obtaining PDI values higher than 0.5 (Fig. 6b). Moreover, the presence of calcium carbonate in samples also can increase their heterogeneity in respect to particles size. However, the admixture of colloidal $\mathrm{CaCO}_{3}$ reinforce of nanocellulose films and allow to prepare more advanced forms of composites (Dimic-Misic et al. 2016; Wei et al. 2014). Barbash et al. (2016) have postulated that diversity of nanocellulose particles size can facilitate the film formation and improve its density and transparency.

All studied aqueous samples of ACNF/PCC revealed negative surface charge of particles (Fig. 6c) what is comparable with other published data (Jiang and Hsieh 2013; Prathapana et al. 2016; Wei et al. 2014). The use of oxidative agent $(\mathrm{NaClO})$ in the extraction procedure (Szymańska-Chargot et al. 2017) can result in the hydroxyl groups oxidation to carboxyl ones, which are dissociated in water at neutral $\mathrm{pH}$ (Wei et al. 2014). The low absolute value of both EM and ZP at big size of non-sonicated nanocellulose/ PCC particles (Fig. 6a, c) suggest that the sample was flocculated. The application of ultrasounds led to form smaller particles which move faster in electric field or/ and possess higher negative surface charge. The lack of statistically significant differences in the electrophoretic mobility values of sonicated samples points out that neither the power nor duration of ultrasounds action didn't influence the electrical charge to particles size ratio (Delgado et al. 2007). Therefore, the power of $40 \mathrm{~W}$ was sufficient to obtain well dispersed systems (Fig. 6). An increase of sonication time resulted only in more homogeneous size of dispersed particles.

The use of tap water in all stages of the plant biomass fractionation (Szymańska-Chargot et al. 
2017) resulted in the presence of divalent cations and the $\mathrm{CaCO}_{3}$ precipitation in nanocellulose solution. Zeta potential as well as the surface electrical charge of calcium carbonate dispersed in distilled water at $\mathrm{pH}$ range of $7-8$ is positive (Eriksson et al. 2007). Interaction of negatively charged cellulose particles with the divalent cations leads to the nanofibers linking (e.g. calcium bridges formation). Additionally, the immobilization of positively charged calcite particles in nanocellulose matrix lowers their electrical charge and reduces an inter-particles repulsion (Liu et al. 2017). Moreover, the hydrogen bonding between the $-\mathrm{OH}$ group of cellulose and inorganic particles can be formed (Ma et al. 2012). As a result of these processes, which occurred during the nanocellulose preparation, the obtained non-sonicated sample was highly flocculated. The ultrasounds, besides of nanocellulose particles fragmentation favor the $\mathrm{CaCO}_{3}$ crystals synthesis what could increase homogeneity of nanocellulose/PCC systems in respect to the particles size (Fu et al. 2013).

The initial ultrasounds application resulted in the obtaining smaller particles with higher negative surface charge. However, the generated electrostatic repulsion between the dispersed particles was not sufficient to prevent the further coagulation, flocculation and gelation processes during the samples storage. Nanofibrillated cellulose forms a gellike material even at low concentrations and this effect can be enhanced by the presence of calcite (Liu et al. 2017). The positively charged PCC facilitates the nanocellulose flocculation and dewatering of the samples (DimicMisic et al. 2017; Nypelo et al. 2012; Liu et al. 2017). The obtained results are consistent with this literature information. For non-sonicated sample the transparent water layer over the suspension layer of flocculated particles could be noted after a few days of storage (Fig. S2). The loss of water from ultrasonicallydispersed systems containing small particles was partly slowed down by the binding of water in hydration layers around particles. On the other hand, it was observed that, the higher ultrasonication power was applied (smaller particle, higher absolute values of EM and ZP), the lower concentration of nanocellulose/PCC was necessary to gel formation and more rapid flocculation occured (increase of $\mathrm{Rd}_{h}$ ). This can be explained by high diffusion coefficient of small particles which leads to their effective collisions. The overcome of electrostatic repulsion between particles, the attraction amongst oppositely charged particles present in the system is facilitated. Moreover, the increase of the samples concentration facilitates the formation of hydrogen bonds between nanocellulose fibrils as showed in previous study (Dimic-Misic et al. 2017; Nypelo et al. 2012; Liu et al. 2017).

Finally, the mechanical properties of nanopapers obtained on the basis of dispersions were investigated. The ultrasounds application improved the mechanical properties of composites. Both elastic modulus and tensile strength increased. On the average the elastic modulus ranged between 2.2 and $3.1 \mathrm{GPa}$, while the tensile strength ranged from 48 to $70 \mathrm{MPa}$. The mechanical properties of cellulose nanopapers may strongly depend on the cellulose origin, nanocellulose fabrication method as well as the method of nanopaper preparation. For example, elastic moduli of nanopaper from sugar beet pulp cellulose prepared by solvent casting method was 2.5 GPa (Dufresne et al. 1997) while for the nanopaper made of birch wood cellulose prepared by spray deposition was even $21 \mathrm{GPa}$ (Beneventi et al. 2015). Tensile strength was 10 to even $312 \mathrm{MPa}$, respectively in these two cases. However, the elastic moduli obtained for hybrid nanopapers of nanocellulose/calcium carbonate oscillated between 1 and $3 \mathrm{GPa}$ with tensile strength around 40-50 MPa (Oun and Rhim 2015; Gebauer et al. 2011; Saito et al. 2014).

\section{Conclusions}

This paper presents the study of structural, rheological and physico-chemical properties of nanofibrillated apple cellulose (ACNF)/precipitated calcium carbonate (PCC) composites. The calcium carbonate was directly precipitated in the presence of cellulose fibers isolated from apple pomace. Different conditions (time and power) of ultrasounds were used to fibrillate the cellulose and resulted in acquisition dispersions of ACNF/PCC. AFM microscopy confirms the nanofibrillated structure of cellulose after the use of ultrasounds. Whereas, SEM micrographs showed that use of ultrasounds induced formation of calcium carbonate as cubic and rods instead of spherical forms as it was in the case of untreated sample (M0t0). Ultrasounds change rheological properties of the ACNF/ PCC aqueous suspensions, but regardless power and time of ultrasonication suspensions could be classified 
as pseudoplastic fluids with viscosity and thixotropic effect greater than for the untreated sample. The mean hydrodynamic diameter of particle dispersions decreased after use of ultrasounds for $60 \mathrm{~min}$. Nevertheless, shorter time's periods did not influence much the mean hydrodynamic diameter comparing with control sample. Moreover, the longer ultrasounds application caused that the obtained dispersions were more homogeneous. Based on that it can be conclude that low-power ultrasounds are sufficient to produce the stable ACNF/PCC system.

Acknowledgments The work was partially funded by The National Centre for Research and Development—Poland (Grant No. LIDER/300/L-6/14/NCBR/2015).

Open Access This article is distributed under the terms of the Creative Commons Attribution 4.0 International License (http:// creativecommons.org/licenses/by/4.0/), which permits unrestricted use, distribution, and reproduction in any medium, provided you give appropriate credit to the original author(s) and the source, provide a link to the Creative Commons license, and indicate if changes were made.

\section{References}

Abdel-Aal N, Satoh K, Sawada K (2002) Study of the adhesion mechanism of $\mathrm{CaCO}_{3}$ using a combined bulk chemistry/ QCM technique. J Cryst Growth 245:87-100

Agoda-Tandjawa G, Durand S, Berot S, Blassel C, Gaillard C, Garnier C, Doublier J-L (2010) Rheological characterization of microfibrillated cellulose suspensions after freezing. Carbohydr Polym 80:677-686

Ahvenainen P, Kontro I, Svedström K (2016) Comparison of sample crystallinity determination methods by X-ray diffraction for challenging cellulose I materials. Cellulose 23:1073-1086

Ämmälä A, Liimatainen H, Burmeister C, Niinimäki J (2013) Effect of TEMPO and periodate-chlorite oxidized nanofibrils on ground calcium carbonate flocculation and retention in sheet forming and on the physical properties of sheets. Cellulose 20:2451-2460

Azizi Samir MAS, Alloin F, Dufresne A (2005) Review of recent research into cellulosic whiskers, their properties and their application in nanocomposite field. Biomacromolecules 6(2):612-626

Barbash VA, Yaschenko OV, Alushkin SV, Kondratyuk AS, Posudievsky OY, Koshechko VG (2016) The effect of mechanochemical treatment of the cellulose on characteristics of nanocellulose films. Nanoscale Res Lett $11: 410$

Beneventi D, Zeno E, Chaussy D (2015) Rapid nanopaper production by spray deposition of concentrated microfibrillated cellulose slurries. Ind Crops Prod 72:200-205
Bercea M, Navard P (2000) Shear dynamics of aqueous suspensions of cellulose whiskers. Macromolecules 33(16):6011-6016

Brinchia L, Cotana F, Fortunati E, Kenny JM (2013) Production of nanocrystalline cellulose from lignocellulosic biomass: technology and applications. Carbohyd Polym 94:154-169

Chen W, Yu H, Liu Y, Chen P, Zhang M, Hai Y (2011a) Individualization of cellulose nanofibers from wood using high-intensity ultrasonication combined with chemical pretreatments. Carbohydr Polym 83(4):1804-1811

Chen W, Yu H, Liu Y, Hai Y, Zhang M, Chen P (2011b) Isolation and characterization of cellulose nanofibers from four plant cellulose fibers using a chemical-ultrasonic process. Cellulose 18(2):433-442

Chen P, Yu H, Liu Y, Chen W, Wang X, Ouyang M (2013) Concentration effects on the isolation and dynamic rheological behavior of cellulose nanofibers via ultrasonic processing. Cellulose 20:149-157

Chylinska M, Szymanska-Chargot M, Kruk B, Zdunek A (2016) Study on dietary fibre by Fourier transform-infrared spectroscopy and chemometric methods. Food Chem 194:86-94

Cizer Ö, Rodriguez-Navarro C, Ruiz-Agudo E, Elsen J, Van Gemert D, Van Balen K (2012) Phase and morphology evolution of calcium carbonate precipitated by carbonation of hydrated lime. J Mater Sci 47:6151-6165

Declet A, Reyes E, Suárez OM (2016) Calcium carbonate precipitation: a review of the carbonate crystallization process and applications in bioinspired composites. Rev Adv Mater Sci 44:87-107

Delgado AV, Gonzales-Caballero F, Hunter RJ, Koopal LK, Lyklema J (2007) Measurement and interpretation of electrokinetic phenomena. J Colloid Interface Sci 309:194-224

Dhillon GS, Kaur S, Brar SK (2013) Perspective of apple processing wastes as low-cost substrates for bioproduction of high value products: a review. Renew Sustain Energy Rev 27:789-805

Dimic-Misic K, Gane P, Paltakari J (2013) Micro- and nanofibrillated cellulose as a rheology modifier additive in CMC-containing pigment-coating formulations. Ind Eng Chem Res 52:16066-16083

Dimic-Misic K, Rantanen J, Maloney TC, Gane PAC (2016) Gel structure phase behavior in micro nanofibrillated cellulose containing in situ precipitated calcium carbonate. J Appl Polym Sci. https://doi.org/10.1002/APP.43486

Dimic-Misic K, Maloney T, Liu G, Gane P (2017) Micro nanofibrillated cellulose (MNFC) gel dewatering induced at ultralow-shear in presence of added colloidally unstable particles. Cellulose 24:1463-1481

Dinand E, Chanzy H, Vignon MR (1996) Parenchymal cell cellulose from sugar beet pulp: preparation and properties. Cellulose 3:183-188

Dolz M, Hernández MJ, Delegido J, Alfaro MC, Muñoz J (2007) Influence of xanthan gum and locust bean gum upon flow and thixotropic behaviour of food emulsions containing modified starch. J Food Eng 81:179-186

Dufresne A, Cavaillé J-Y, Vignon MR (1997) Mechanical behavior of sheets prepared from sugar beet cellulose microfibrils. J Appl Polym Sci 64(6):1185-1194 
Eriksson R, Merta J, Rosenholm JB (2007) The calcite/water interface I. Surface charge in indifferent electrolyte media and the influence of low-molecular-weight polyelectrolyte. J Colloid Interface Sci 313:184-193

Fan M, Dai D, Huang B (2012) Fourier transform infrared spectroscopy for natural fibres. In: Salih $\mathrm{S}$ (ed) Fourier transform-materials analysis. InTech, Crotia. ISBN 978-953-51-0594-7

French AD (2014) Idealized powder diffraction patterns for cellulose polymorphs. Cellulose 21(3):885-896

Fu L-H, Dong Y-Y, Ma M-G, Li S-M, Sun R-C (2013) Compare study $\mathrm{CaCO}_{3}$ crystals on the cellulose substrate by microwave-assisted method and ultrasound agitation metod. Ultrason Sonochem 20:839-845

Gebauer D, Oliynyk V, Salajkova M, Sort J, Zhou Q, Bergström L, Salazar-Alvarez G (2011) A transparent hybrid of nanocrystalline cellulose and amorphous calcium carbonate nanoparticles. Nanoscale 3:3563-3566

Guo H, Qin Z, Qian P, Yu P, Cui S, Wang W (2011) Crystallization of aragonite $\mathrm{CaCO}_{3}$ with complex structures. Adv Powder Technol 22:777-783

Heinze T (2016) Cellulose: structure and properties. In: Rojas O (ed) Cellulose chemistry and properties: fibers, nanocelluloses and advanced materials. Advances in polymer science. Springer, Berlin

Hubbe MA, Tayeb P, Joyce M, Tyagi P, Kehoe M, Dimic-Misic K, Pal L (2017a) Nanocellulose rheology. BioRes 12(4):9556-9661

Hubbe MA, Ferrer A, Tyagi P, Yin Y, Salas C, Pal L, Rojas OJ (2017b) Nanocellulose in thin films, coatings, and piles for packing applications: a review. BioRes 12:2143-2233

ISO 13321 (1996) Particle size analysis-photon correlation spectroscopy, international organization for standardization

Jiang F, Hsieh Y-L (2013) Chemically and mechanically isolated nanocellulose and their self-assembled structures. Carbhydr Polym 95:32-40

Jiang F, Hsieh Y-L (2015) Cellulose nanocrystal isolation from tomato peels and assembled nanofibers. Carbohydr Polym 122:60-68

Kačurakova M, Smith AC, Gidley MJ, Wilson RH (2002) Molecular interactions in bacterial cellulose composites studied by 1D FT-IR and dynamic 2D FT-IR spectroscopy. Carbohydr Res 337:1145-1153

Karppinen A, Saarinen T, Salmela J, Laukkanen A, Nuopponen M, Seppälä J (2012) Flocculation of microfibrillated cellulose in shear flow. Cellulose 19:1807-1819

Kaszuba M, McKnight D, Connah MT, McNeil-Watson FK, Nobbmann U (2008) Measuring sub nanometre sizes using dynamic light scattering. J Nanopart Res 10:823-829

Khalil HPSA, Bhat AH, Ireana Yusra AF (2012) Green composites from sustainable cellulose nanofibrils: a review. Carbohydr Polym 87:963-979

Klinkaewnarong J, Utara S (2018) Ultrasonic-assisted conversion of limestone into needle-like hydroxyapatite nanoparticles. Ultrason Sonochem 46:18-25

Li Q, Renneckar SH (2011) Supramolecular structure characterization of molecularly thin cellulose I nanoparticle. Biomacromol 12:650-659

Liu G, Maloney T, Dimic-Misic K, Gane P (2017) Acid dissociation of surface bound water on cellulose nanofibrils in aqueous micro nanofibrillated (MNFC) gel revealed by adsorption of calcium carbonate nanoparticles under the application of ultralow shear. Cellulose 24:3155-3178

Lu Q, Cai Z, Wang S, Lin F, Lu B, Chen Y, Huang B (2017) Controlled construction of nanostructured organic-inorganic hybrid material induced by nanocellulose. ACS Sustain Chem Eng 5(9):8456-8463

Ma MG, Fu L-H, Sun R-C, Jia N (2012) Compared study on the cellulose $/ \mathrm{CaCO}_{3}$ composites via microwave-assisted method using different cellulose types. Carbohyd Polym 90:309-315

Maestri CA, Abrami M, Hazan S, Chistè E, Golan Y, Rohrer J, Bernkop-Schnürch A, Grassi M, Scarpa M, Bettotti P (2017) Role of sonication pre-treatment and cation valence in nano-cellulose suspensions sol-gel transition. Sci Rep 7:11129

Mayinger F (1994) Optical measurements techniques and applications. Springer, Berlin

Mierczyńska J, Cybulska J, Zdunek A (2017) Rheological and chemical properties of pectin enriched fractions from different sources extracted with citric acid. Carbohydr Polym 156:443-451

Mirabella N, Castellani V, Sala S (2014) Current options for the valorization of food manufacturing waste: a review. J Clean Prod 65:28-41

Moberg T, Sahlin K, Yao K, Geng S, Westman G, Zhou Q, Oksman K, Rigdahl M (2017) Rheological properties of nanocellulose suspensions: effects of fibril/particle dimensions and surface characteristics. Cellulose 24:2499-2510

Mohammadkazemi F, Faria M, Cordeiro N (2016) In situ biosynthesis of bacterial nanocellulose- $\mathrm{CaCO}_{3}$ hybrid bionanocomposite: one-step process. Mat Sci Eng C Mater 65:393-399

Moon RJ, Martini A, Nairn J, Simonsen J, Youngblood J (2011) Cellulose nanomaterials review: structure, properties and nanocomposites. Chem Soc Rev 40:3941-3994

Myśliwiec D, Szcześ A, Chibowski S (2016) Influence of static magnetic field on the kinetics of calcium carbonate formation. J Ind Eng Chem 35:400-407

Nechyporchuk O, Belgacem MN, Pignon F (2014) Rheological properties of micro-/nanofibrillated cellulose suspensions: wall-slip and shear banding phenomena. Carbohydr Polym 112:432-439

Niklas KJ (1992) Plant biomechanics: an engineering approach to plant form and function. University of Chicago Press, Chicago

Nypelo T, Pynnonen H, Osterberg M, Paltakari J, Laine J (2012) Interactions between inorganic nanoparticles and cellulose nanofibrils. Cellulose 19:779-792

Osong SH, Norgren S, Engstrand P (2016) Processing of woodbased microfibrillated cellulose and nanofibrillated cellulose, and applications relating to papermaking: a review. Cellulose 23:93-123

Oun AA, Rhim J-W (2015) Preparation and characterization of sodium carboxymethyl cellulose/cotton linter cellulose nanofibril composite films. Carbohydr Polym 127:101-109

Prathapana R, Thapaa R, Garnierb G, Tabora RF (2016) Modulating the zeta potential of cellulose nanocrystals using salts and surfactants. Colloids Surf A Physicochem Eng Asp 509:11-18 
Quarterly Water Quality Report 2017 for a Municipal Water and Sewage Company in Lublin, Poland (in Polish). https:// mpwik.sni.pl//imgs_upload2/laboratorium/wskazniki\% 20II\%20kw\%202017.jpg. Accessed 09 May 2018

Quennouz N, Hashmi SM, Choi HS, Kim JW, Osuji CO (2016) Rheology of cellulose nanofibrils in the presence of surfactants. Soft Matter 12(1):157-164

Rabetafika HN, Bchir B, Blecker C, Richel A (2014) Fractionation of apple by-products as source of new ingredients: current situation and perspectives. Trends Food Sci Technol 40:99-114

Roland JC, Reis D, Vian B, Roy S (1989) The helicoidal plant cell wall as a performing cellulose-based composite. Biol Cell 67:209-220

Saito T, Oaki Y, Nishimura T, Isogai A, Kato T (2014) Bioinspired stiff and flexible composites of nanocellulose-reinforced amorphous $\mathrm{CaCO}_{3}$. Mater Horizons 1(3):321

Stoica-Guzun A, Stroescu M, Jinga S, Jipa I, Dobre T, Dobre L (2012) Ultrasound influence upon calcium carbonate precipitation on bacterial cellulose membranes. Ultrason Sonochem 19:909-915

Subramanian R, Hiltunen W, Gane PAC (2011) Potential use of micro- and nanofibrillated cellulose composites exemplified by paper. In: Kalita S et al (eds) Cellulose fibers: bioand nano-polymer composites. Springer, Berlin
Szymańska-Chargot M, Zdunek A (2013) Use of FT-IR spectra and PCA to the bulk characterization of cell wall residues of fruits and vegetables along a fraction process. Food Biophys 8:29-42

Szymańska-Chargot M, Chylińska M, Kruk B, Zdunek A (2015) Combining FT-IR spectroscopy and multivariate analysis for qualitative and quantitative analysis of the cell wall composition changes during apples development. Carbohydr Polym 115:93-103

Szymańska-Chargot M, Chylińska M, Gdula K, Kozioł A, Zdunek A (2017) Isolation and characterization of cellulose from different fruit and vegetable pomaces. Polymers 9:495

Vagenas NV, Gatsouli A, Kontoyannis CG (2003) Quantitative analysis of synthetic calcium carbonate polymorphs using FT-IR spectroscopy. Talanta 59:831-836

Wei H, Rodriguez K, Renneckar S, Vikesland PJ (2014) Environmental science and engineering applications of nanocellulose-based nanocomposites. Environ Sci Nano $1: 302-316$

Yadav C, Saini A, Maji PK (2017) Energy efficient facile extraction process of cellulose nanofibres andtheir dimensional characterization using light scattering techniques. Carbhydr Polym 165:276-284 